\title{
Linking employee burnout to medical aid provider expenditure
}

\author{
L de Beer, J Pienaar, S Rothmann Jr
}

WorkWell Research Unit, North-West University, Potchefstroom

L de Beer, MCom Industrial Psychology

J Pienaar, PhD Industrial Psychology

Afriforte (Pty) Ltd (Commercial Arm of the WorkWell Research Unit)

$\mathrm{S}$ Rothmann Jr, MSc

Corresponding author: $L$ de Beer (leondb@gmail.com)

\begin{abstract}
Background. Healthcare has become a major expense. Burnout and its connection with psychological and physical health is well researched, yet little research has been done on the connection between burnout and financial outcomes, specifically as indicated by the costs incurred by medical aid providers as a result of members' claims.

Objective. To investigate the connection between employee burnout and medical aid claims and expenditure data in a sample from the private sector.

Method. A cross-sectional design was used. The sample comprised 3182 participants. The available objective medical aid expenditure data connected with each participant were: total insured benefits, general practitioner visits, specialist visits, general practitioner insured benefits, and claims for medicine. A low and a high burnout group were extracted, based on comorbidity of the two core components of burnout. Analysis of covariance (ANCOVA) was then applied to investigate the differences in estimated marginal means of the expenditures on the low and the high burnout contrast groups, while controlling for age and gender.

Results. The high burnout group frequented a general practitioner more often, and the medical aid provider expenditure was nearly double that of the low burnout group, on all the variables. Specialist visits did not show a significant result.

Conclusion. High burnout is associated with a higher expenditure by a medical aid provider, compared with low burnout, per member Stakeholders should therefore address burnout to reduce expenditure and promote health.

S Afr Med J 2013;103(2):89-93. DOI:10.7196/SAMJ.6060
\end{abstract}

Healthcare has become a major macro- and micro-cause of expenditure. In South Africa, the public health sector (which provides healthcare to $86 \%$ of the population) accounts for $40 \%$ of healthcare spending. The private sector services the remaining $14 \%$ of the population, and accounts for $60 \%$ of healthcare spending. Total healthcare expenditure in South Africa is higher than in most other upper-middle-income countries and similar to some high-income countries, but the health status indicators are worse than in other countries with the same level of economic development. Large socioeconomic inequalities remain as a result of the apartheid legacy, i.e. high unemployment, poverty, and a high crime rate. Furthermore, South Africa has a high HIV incidence (estimated at $11.9 \%$ of the 
population in 2007 and a total number of 5.7 million cases in 2009). Spending on healthcare services and related products is expected to increase rapidly during 2010 to $2014{ }^{1,2}$

Since May 2012, the South African Rand (ZAR) has averaged R7.46 to US $\$ 1.00$ over a 10 -year period. In 2010 , the total private expenditure on healthcare per capita was R10 011.32 (US\$1 342), and public healthcare per capita was R2 566.24 (US\$344) in South Africa. ${ }^{3}$ A major disparity therefore exists between private and public healthcare expenditure. Furthermore, the South African government is developing a national health insurance system to enable access by the entire population to healthcare according to their needs. Establishing such a system has risks, especially financing for the uninsured, which may lead to rising private sector costs. ${ }^{4}$

The World Health Organization states that work stress can lead to physical health consequences such as heart disease, disorders of the digestive system, raised blood pressure and musculoskeletal disorders. ${ }^{5}$ Psychological distress has also been implicated in an increased risk of coronary heart disease. ${ }^{6}$

Burnout is a state of physical, mental and emotional exhaustion caused by a depletion in the ability to cope with the on-going demands of daily living. ${ }^{7}$ Exhaustion (lack of energy) and cynicism (a negative, indifferent, overly detached attitude) are the two core components of burnout. ${ }^{8}$ The seriousness of burnout becomes apparent with a finding that burnout may be a risk factor for overall survival. ${ }^{9}$

Burnout is currently not classified in the Diagnostic and Statistical Manual of Mental Disorders (DSM-IV-TR), but is listed in the International Statistical Classification of Diseases and Related Health Problems (ICD-10) under 'Problems related to life-management difficulty' (Z73.0). Burnout has an association with anxiety, somatic complaints and depression symptomatology. ${ }^{10}$ Despite burnout and depression sharing common symptoms (such as fatigue, concentration issues and low energy), they are distinct and separable constructs. ${ }^{11}$

Burnout and one of its main components - exhaustion - have also been connected with arteriosclerotic disease, cardiovascular disease, elevated cortisol levels, diabetes, insomnia, and poor self-rated health. ${ }^{12,13}$ Despite the literature connecting burnout to physical health, researchers need to investigate other objective data. Our study attempts to connect burnout with medical aid expenditure; it was approved by North-West University's Faculty Research Committee.

We extracted a high and a low burnout group from the sample and studied their differences on the objective expenditure data. The study hypotheses are:

1. The high burnout group will, more often than the low burnout group, frequent:

1.1 general practitioners (GP visits)

1.2 specialists (SP visits).

2. Insured benefit claims will differ significantly for the low and high burnout groups with regard to:

2.1 total insured benefits

2.2 general practitioner insured benefits.

3. The high burnout group will claim more for medicinal purchases than the low burnout group.

\section{Methods}

A survey design was used by conducting random individual crosssectional surveys as part of a consultation project in a large private sector organisation. A random sample of 3182 employees of all ages and levels of education was used; response rate was $72.3 \%$ (Table 1). Anonymity of all the participants was maintained.
Ethical guidelines in the treatment of human subjects in research were observed.

Of the total sample, 2032 (63.9\%) were female and 1150 (36.1\%) were male. Participants from the 20 - 39-year age groups were in the majority. The most prevalent home languages were English (with 1434 (45.1\%) participants) and Afrikaans with 909 (28.6\%). Married employees numbered 1400 (44.0\%), and 1283 (40.3\%). were single. Of the participants, 1729 (54.3\%), had a general high school education (Grade 12); 732 (23.0\%) had a 3-year degree/diploma, and 317 (10.0\%) had a 4-year university degree/diploma; 2466 (77.5\%), were from Gauteng Province.

\section{Measuring instrument}

The South African Employee Health and Wellness Survey (SAEHWS) was developed as a self-administered survey for application in organisational diagnoses by our Research Unit. The internal consistency of all the subscales of the SAEHWS is highly acceptable compared with the generally accepted alpha-coefficient guideline (i.e. $\alpha \geq 0.70) .^{14}$

Burnout was measured by its two core components: exhaustion and cynicism. These were measured by Likert scales: Exhaustion: $(\alpha=0.80)$ by 5 items e.g. 'I feel tired before I arrive at work'; Cynicism: ( $\alpha=0.75)$ by 4 items e.g. 'I am uncertain whether my work is important'.

Medical claims expenditure data were made available by the medical aid organisation for each respondent. Anonymity of the organisation and the participants was assured; the only identifier was a unique but arbitrary number to connect the correct respondent with the correct data from the medical claims data to ensure accuracy for the data analyses. No identifying information was made available to any party after analyses. The available claims data detailed expenditure on total insured benefits, number of general practitioner (GP) visits, specialist visits, insured benefit GP claims, and claims for medication. All the medical aid expenditure data were for a 6-month period connected to participants and not their total medical plan that might include dependants, which adds to the accuracy and validity of the findings.

\section{Statistical analyses}

A high burnout group and a low burnout group were extracted. The high burnout group included individuals in the 80th, 90th and 100th percentile of burnout, i.e. exhaustion and cynicism scores; therefore this comorbidity was a strict requirement for inclusion in this group. In contrast, the 10th, 20th and 30th percentile of burnout (i.e. exhaustion and cynicism scores) were then grouped together to constitute the low burnout group. The remaining participants constituted an unused population and were not included.

To test the hypotheses, analysis of covariance (ANCOVA) was performed on the low and high burnout groups, while controlling for age and gender as covariates. Levene's test was applied to ascertain the homogeneity of the variances. The variances were found to be homogeneous. The Bonferroni correction was selected to limit the occurrence of Type I errors; it is also valid for equal and unequal sample sizes.

\section{Results}

Table 2 lists the estimated marginal means with confidence intervals of $95 \%$ from the ANCOVA analysis for each group based on the variables under investigation. It shows that differences obtained from the ANCOVA analyses were all significant at the $p<0.05$ level, except specialist visits $(p=0.776)$.

GP visits (Fig. 1): The ANCOVA results indicated that both age, $F(1,1002)=17.85 ; p<0.001$, and gender, $F(1,1002)=30.03 ; p<0.001$ 


\section{RESEARCH}

Table 1. Characteristics of the total sample $(N=3$ 182) and the burnout groups

\begin{tabular}{|c|c|c|c|c|c|c|c|c|c|}
\hline \multirow[b]{2}{*}{ Item } & \multirow[b]{2}{*}{ Category } & \multicolumn{2}{|c|}{$\begin{array}{l}\text { Total sample } \\
(N=3 \text { 182) }\end{array}$} & \multicolumn{2}{|c|}{$\begin{array}{c}\text { Low burnout } \\
(n=236)\end{array}$} & \multicolumn{2}{|c|}{$\begin{array}{l}\text { Unused population } \\
\qquad(n=2176)\end{array}$} & \multicolumn{2}{|c|}{$\begin{array}{l}\text { High burnout } \\
\quad(n=770)\end{array}$} \\
\hline & & Frequency & $\%$ & Frequency & $\%$ & Frequency & $\%$ & Frequency & $\%$ \\
\hline \multirow[t]{2}{*}{ Gender } & Male & 1150 & 36.14 & 124 & 52.54 & 809 & 37.18 & 217 & 28.18 \\
\hline & Female & 2032 & 63.86 & 112 & 47.46 & 1367 & 62.82 & 553 & 71.81 \\
\hline \multirow[t]{6}{*}{ Age (years) } & $<20$ & 3 & 0.01 & 0 & 0.00 & 3 & 0.14 & 0 & 0.00 \\
\hline & $20-29$ & 1043 & 32.78 & 42 & 17.80 & 670 & 30.79 & 331 & 42.99 \\
\hline & $30-39$ & 1062 & 33.38 & 71 & 30.08 & 748 & 34.38 & 243 & 31.56 \\
\hline & $40-49$ & 630 & 19.80 & 66 & 27.97 & 433 & 19.90 & 131 & 17.01 \\
\hline & $50-59$ & 378 & 11.88 & 42 & 17.80 & 279 & 12.82 & 57 & 7.40 \\
\hline & $>60$ & 66 & 2.07 & 15 & 6.36 & 43 & 1.98 & 8 & 1.04 \\
\hline \multirow[t]{6}{*}{ Marital status } & Single & 1283 & 40.32 & 68 & 28.81 & 866 & 39.80 & 349 & 45.32 \\
\hline & Engaged & 156 & 4.90 & 3 & 1.27 & 103 & 4.73 & 50 & 6.49 \\
\hline & Married & 1400 & 44.00 & 137 & 58.05 & 954 & 43.84 & 309 & 40.13 \\
\hline & Divorced & 289 & 9.08 & 22 & 9.32 & 214 & 9.83 & 53 & 6.88 \\
\hline & Widow & 50 & 1.57 & 6 & 2.54 & 36 & 1.65 & 8 & 1.04 \\
\hline & Widower & 4 & 0.13 & 0 & 0.00 & 3 & 0.14 & 1 & 0.13 \\
\hline \multirow[t]{12}{*}{ Language } & Afrikaans & 909 & 28.57 & 70 & 29.66 & 605 & 27.80 & 234 & 3.39 \\
\hline & English & 1434 & 45.06 & 89 & 37.71 & 1009 & 46.37 & 336 & 43.64 \\
\hline & Sepedi & 131 & 4.12 & 12 & 5.08 & 96 & 4.41 & 23 & 2.99 \\
\hline & Sesotho & 120 & 3.77 & 10 & 4.24 & 78 & 3.58 & 32 & 4.16 \\
\hline & Setswana & 178 & 5.59 & 21 & 8.90 & 115 & 5.28 & 42 & 5.45 \\
\hline & Siswati & 15 & 0.47 & 1 & 0.42 & 7 & 0.32 & 7 & 0.91 \\
\hline & Tshivenda & 27 & 0.85 & 3 & 1.27 & 16 & 0.74 & 8 & 1.04 \\
\hline & isiZulu & 211 & 6.63 & 18 & 7.63 & 144 & 6.62 & 49 & 6.36 \\
\hline & isiNdebele & 21 & 0.66 & 3 & 1.27 & 15 & 0.69 & 3 & 0.39 \\
\hline & isiXhosa & 92 & 2.89 & 2 & 0.85 & 66 & 3.03 & 24 & 3.12 \\
\hline & Xitsonga & 35 & 1.10 & 5 & 2.12 & 19 & 0.87 & 11 & 1.43 \\
\hline & Other & 9 & 0.28 & 2 & 0.85 & 6 & 0.28 & 1 & 0.13 \\
\hline \multirow[t]{9}{*}{ Education } & Grade 8 & 23 & 0.72 & 4 & 1.69 & 16 & 0.74 & 3 & 0.39 \\
\hline & Grade 9 & 21 & 0.66 & 2 & 0.85 & 15 & 0.69 & 4 & 0.52 \\
\hline & Grade 10 & 126 & 3.96 & 10 & 4.24 & 75 & 3.45 & 41 & 5.32 \\
\hline & Grade 11 & 51 & 1.60 & 3 & 1.27 & 39 & 1.79 & 9 & 1.17 \\
\hline & Grade 12 & 1729 & 54.34 & 117 & 49.58 & 1166 & 53.58 & 446 & 57.92 \\
\hline & 3-year degree & 732 & 23.00 & 63 & 26.69 & 510 & 23.44 & 159 & 20.65 \\
\hline & 4-year degree & 317 & 9.96 & 21 & 8.90 & 221 & 10.16 & 75 & 9.74 \\
\hline & Master's degree & 176 & 5.53 & 15 & 6.36 & 129 & 5.93 & 32 & 4.16 \\
\hline & Doctoral degree & 7 & 0.22 & 1 & 0.42 & 5 & 0.23 & 1 & 0.13 \\
\hline \multirow[t]{9}{*}{ Province } & Gauteng & 2466 & 77.50 & 169 & 71.61 & 1719 & 79.00 & 578 & 75.06 \\
\hline & Mpumalanga & 36 & 1.13 & 6 & 2.54 & 21 & 0.97 & 9 & 1.17 \\
\hline & North West & 25 & 0.79 & 5 & 2.12 & 12 & 0.55 & 8 & 1.04 \\
\hline & Limpopo & 19 & 0.60 & 3 & 1.27 & 7 & 0.32 & 9 & 1.17 \\
\hline & Free State & 72 & 2.26 & 8 & 3.39 & 33 & 1.52 & 31 & 4.03 \\
\hline & Northern Cape & 14 & 0.44 & 1 & 0.42 & 6 & 0.28 & 7 & 0.91 \\
\hline & Western Cape & 278 & 8.74 & 18 & 7.63 & 185 & 8.50 & 75 & 9.74 \\
\hline & Eastern Cape & 60 & 1.89 & 6 & 2.54 & 40 & 1.84 & 14 & 1.82 \\
\hline & KwaZulu-Natal & 212 & 6.66 & 20 & 8.47 & 153 & 7.03 & 39 & 5.06 \\
\hline
\end{tabular}




\section{RESEARCH}

Table 2. Estimated marginal means with $95 \%$ confidence intervals

\begin{tabular}{|c|c|c|c|c|c|c|}
\hline \multirow[b]{2}{*}{ Description } & \multirow[b]{2}{*}{ Burnout group } & \multirow[b]{2}{*}{ Mean } & \multirow[b]{2}{*}{ SE } & \multicolumn{3}{|c|}{$95 \% \mathrm{CI}$} \\
\hline & & & & Lower & Upper & $p$-value \\
\hline \multirow[t]{3}{*}{ GP visits } & Low & 2.42 & 0.19 & 2.04 & 2.80 & 0.001 \\
\hline & High & 3.26 & 0.10 & 3.05 & 3.46 & \\
\hline & Difference & 0.84 & & & & \\
\hline \multirow[t]{3}{*}{ Specialist visits } & Low & 1.05 & 0.14 & 0.78 & 1.335 & 0.776 \\
\hline & High & 1.01 & 0.08 & 0.86 & 1.158 & \\
\hline & Difference & 0.04 & & & & \\
\hline \multirow[t]{3}{*}{ GP insured benefits } & Low & 89.18 & 24.34 & 41.42 & 136.94 & 0.014 \\
\hline & High & 158.90 & 13.02 & 133.35 & 184.45 & \\
\hline & Difference & 69.72 & & & & \\
\hline \multirow[t]{3}{*}{ Medicine claims } & Low & 81.93 & 28.41 & 26.18 & 137.68 & 0.016 \\
\hline & High & 161.76 & 15.20 & 131.93 & 191.59 & \\
\hline & Difference & 79.83 & & & & \\
\hline \multirow[t]{3}{*}{ Total insured benefits } & Low & 2411.45 & 919.79 & 606.52 & 4216.37 & 0.010 \\
\hline & High & 5148.75 & 492.12 & 4183.05 & 6114.45 & \\
\hline & Difference & 2737.30 & & & & \\
\hline
\end{tabular}

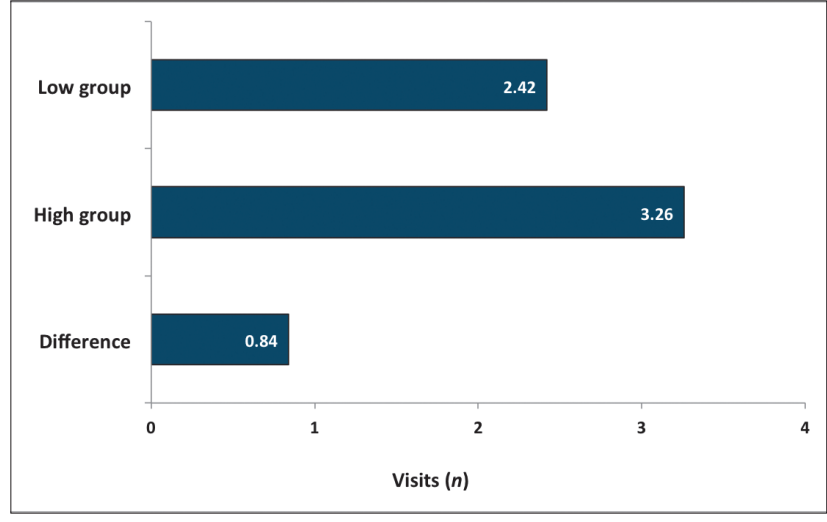

Fig. 1. Difference in GP visits per burnout group.

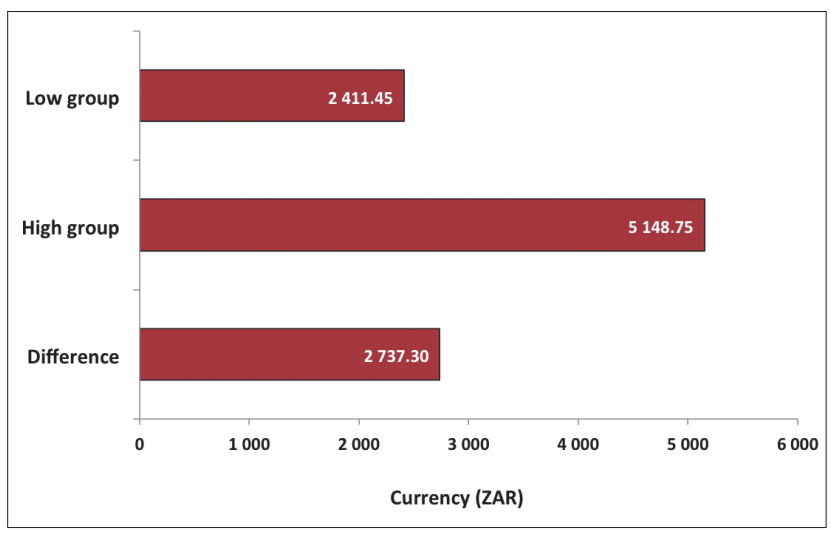

Fig. 3. Difference in the total insured benefits claims per burnout group.

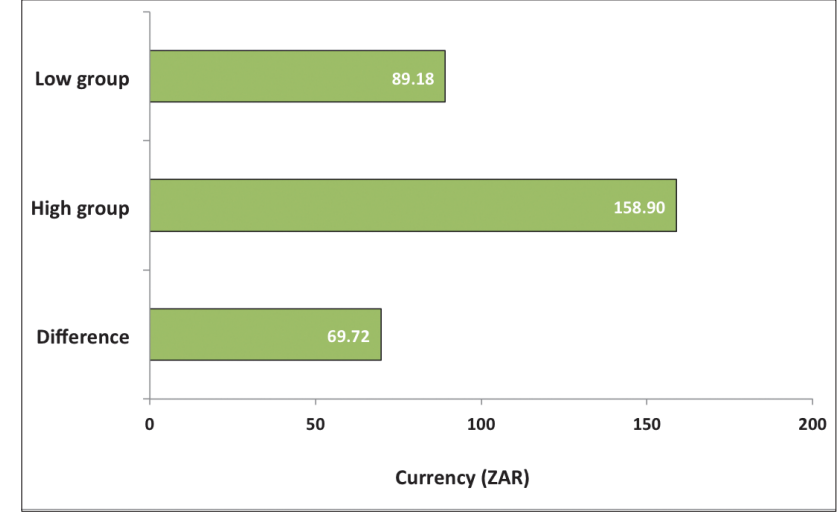

Fig. 2. Difference in GP-insured benefits claims per burnout group.

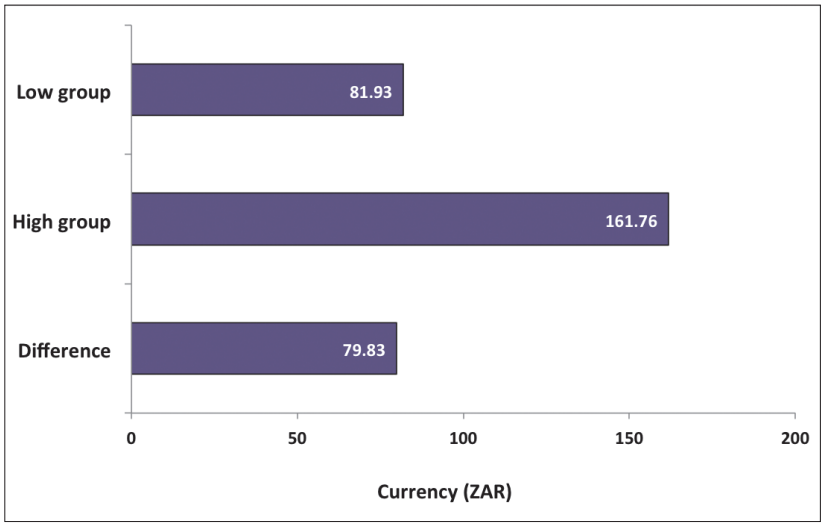

Fig. 4. Difference in medicinal claims per burnout group. 
were significant covariates of GP visits. After controlling for the former, a significant difference was still found; $F(1,1002)=14.08$; $p<0.001$. This result supports hypothesis 1.1 by showing that the high burnout group does frequent the GP on average more often (0.84, or nearly one visit more) than the low burnout group.

Specialist visits: The result of this analysis was not significant, rejecting hypothesis 1.2 .

GP insured benefits (Fig. 2): The ANCOVA analysis indicated that neither the covariate age $(p<0.76)$, nor gender $(p<0.18)$ had a significant impact. However, a significant difference was found between the low and high burnout groups; $F(1,1004)=6.10 ; p<0.014$. This supports hypothesis 2.2 by illustrating that expenditure on the high burnout group is on average higher (by R69.72) than for the low burnout group.

Total insured benefits (Fig. 3): The ANCOVA results indicated that only age, $F(1,1002)=8.01 ; p<0.005$, was a significant covariate. Controlling for the former, a significant difference in total insured benefit claims was found, namely $F(1,1004)=6.59 ; p<0.010$. This demonstrates that expenditure for the high burnout group is R2 737.30 more than the low burnout group, which supports hypothesis 2.1 .

Medicine claims (Fig. 4): The ANCOVA results indicated that only gender, $F(1,1002)=5.64 ; p<0.018$, was a significant covariate Controlling for the former, a significant difference was found, namely $F(1,1004)=5.87 ; p<0.016$. This result supports hypothesis 3 by showing that the high burnout group, on average, claims more (R79.83) than the low burnout group.

\section{Discussion}

All cases in the high burnout group recorded higher values than the low burnout group. The only non-significant result was for specialist visits between the high and low groups. The reason why specialist visits were not significant is most likely that individuals first visit their GP and are only referred to specialists if needed. The GP visit might be the only necessary visit for a diagnosis. This procedure is also often endorsed by medical aid providers.

On average, the high burnout group paid GPs nearly one visit more than the low burnout group. Reasons for this could include that high burnout group individuals realise that something is wrong, or that their health has deteriorated as a result of burnout; this relates to findings that burnout has a detrimental effect on physical health, and probably also perceptions of one's own physical health. ${ }^{12,13}$

All claims were for a 6-month period and not for an entire year. Expenses for medicine claims by the provider for the high burnout group were almost double that of the lower burnout group. This ratio also applies to the total insured benefit claims and insured benefits for GP visits, suggesting that the expenditure on the high burnout group is almost double that of the low burnout group. Despite evidence that stress can add $10 \%$ to estimated work stress costs, the principle of correlation versus causation should be taken into account, e.g. high medical bills may also cause stress in an individual. ${ }^{15}$

Employers, medical aid funds, legislators, and other stakeholders now have further evidence that work-related well-being is an important factor concerning general health and therefore also medical aid claims and expenditure. Therefore, it would be in the interest of employers and medical aid fund administrators to focus on reducing burnout levels in employees to curb their own expenses and the incidence of claims. Burnout may transfer, directly or indirectly, from one person to another (i.e. by contagion) in individuals and work teams. ${ }^{16}$ Employees should therefore guard against burnout by ensuring adequate effortrecovery strategies. They may have to consider leaving their employment if the environment remains adverse and shows no evidence of improvement after avenues of recourse were taken. Otherwise, the health consequences could further be complicated for the employee.

Limitations of this study include its cross-sectional design, and causality should not be inferred. Future research should attempt a longitudinal design and investigation including objective indicators and assessments to ascertain general health status. These could include past and current medical history (physical and mental) of participants, as there may be important confounding variables at work. For example, it is possible that individuals with poor physical or mental health visit GPs more often and are more vulnerable to burnout because of their reduced health status.

South Africa and other countries considering national health insurance systems should focus on the psychological well-being of the labour force through policies and legislation. These could reduce costs in the public and private sectors. Subsidies or tax-breaks for businesses that implement evidence-based, work-related, well-being policies could also be considered.

\section{References}

1. Health of Nations. South Africa: Country Profile and Spending Overview; 2011. http://www healthofnations.com/countries/profile/south-africa (accessed 1 February 2012).

2. Country progress report on the declaration of commitment on HIV/AIDS. United Nations Gener Assembly; 2010. http://www.unaids.org/en/regionscountries/countries/southafrica/ (accessed $10 \mathrm{Ma}$ 2012)

3. Harrison D. An overview of health and healthcare in South Africa 1994-2010: Priorities, progres and prospective new gains; 2009. http://www.doh.gov.za/docs/reports/2010/overview1994-2010.pd (accessed 13 January 2012)

4. Health Systems Trust. Per capita health expenditure; 2011. http://www.healthlink.org.za/ healthstats/78/data (accessed 10 March 2012).

5. Leka S, Griffiths A, Cox T. World Health Organization: Protecting Workers' Health Series. 2004;3:80 6. Stansfeld SA, Fuhrer R, Shipley MJ, Marmot, MG. Psychological distress as a risk factor for coronary heart disease in Whitehall II Study. Int J Epidemiol 2002;31(1):248-255. [http://dx.doi.org/10.1093/ ije/31.1.248]

7. Maslach C. Burnout: The Cost of Caring. Englewood Cliffs, NJ: Prentice-Hall; 1982.

8. Schaufeli WB, Taris TW. The conceptualization and measurement of burnout: common ground and worlds apart. Work and Stress 2005;19(3):256-262. [http://dx.doi.org/10.1080/02678370500385913]

9. Ahola K, Vaananen A, Koskinen A, Kouvonen A, Shirom A. Burnout as a predictor of all-cause mortality among industrial employees: A ten-year prospective register-linkage study.J Psychosom Res 2010;69(1):51-57. [http://dx.doi.org/10.1016/j.jpsychores.2010.01.002]

10. Shirom A, Melamed S, Toker S, Berliner S, Shapira I. Burnout and Health Review: Current Knowledge and Future Research Directions. In: Hodgkinson GP, Ford JK, eds. International Review of Industria and Organizational Psychology. Vol 20. Chichester, UK: John Wiley \& Sons, 2006. [http://dx.do org/10.1002/0470029307.ch7]

11. Schaufeli WB, Enzmann D. The Burnout Companion to Study and Practice: A Critical Analysis. Washington, DC: Taylor \& Francis, 1998

12. Melamed S, Shirom A, Toker S, Berliner S, Shapira I. Burnout and risk of cardiovascular disease Evidence, possible causal paths, and promising research directions. Psychol Bull 2006;132(3):327-353. [http://dx.doi.org/ 10.1037/0033-2909.132.3.327]

13. Melamed S, Shirom A, Toker S, Shapira I. Burnout and risk of type 2 diabetes: A prospective study of apparently healthy employed persons. Psychosom Med 2006;68:863-869. [http://dx.doi. org/10.1097/01.psy.0000242860.24009.fo]

4. Rothmann S, Rothmann JC. The South African Employee Health and Wellness Survey (SAEHWS User Manual. 4th ed. Potchefstroom: Afriforte, 2007.

Golden R. Counting the costs of stress. STATS: Take a quantitative leap; 2004. http://stats.org/ stories/2004/counting_costs_stress_sep23_04.htm (accessed 5 June 2012).

Bakker AB, Van Emmerik H, Euwema MC. Crossover of burnout and engagement in work teams. Work and Occupations 2006;33(4):464-489. [http://dx.doi.org/10.1177/0730888406291310] 